\title{
MIGRACIONES FORZOSAS EN EL MUNDO CLÁSICO: PLUTARCO Y LA CONSTRUCCIÓN SOCIAL DE LA IDENTIDAD
}

\author{
FORCED MIGRATION IN THE CLASSICAL WORLD: PLUTARCH AND THE \\ SOCIAL CONSTRUCTION OF IDENTITY
}

\author{
Pedro A. García-Bilbao \\ Universidad Rey Juan Carlos, Madrid. España/Spain \\ pedro.garcia.bilbao@urjc.es
}

Recibido/Received: 12/05/2012

Modificado/Modified: 24/09/2012

Aceptado/Accepted: 08/10/2012

\section{RESUMEN}

En el mundo clásico greco-latino hubo dos formas de migraciones forzosas muy singulares: ostracismo y destierro. El autor latino Plutarco escribió una obra sobre el exilio en la que expone una teoría sobre la construcción social de la identidad y de la patria. El artículo reflexiona sobre la necesidad de aprender del mundo clásico para comprender mejor los procesos contemporáneos de las migraciones forzosas y su impacto humano.

PALABRAS CLAVE

Plutarco, Migraciones forzosas, destierro, sociología, precursores, mundo clásico.

\section{SUMARIO}

1. Las migraciones forzosas en el mundo clásico: destierro y ostracismo. 2. El ostracismo y la defensa de la democracia en Atenas. 3. El destierro y la pérdida de la ciudadanía como identidad. 4. De consolatio: Puente desde el mundo clásico hasta el presente. 5. Notas a un texto de Plutarco: De exilio. Bibliografía.

\begin{abstract}
In classical Greco-Roman world there were two forms of forced migration very important: ostracism and banishment. The Latin author Plutarch wrote a play about exile in which he outlines a theory of social construction of identity and homeland. Reflects on the need to learn the classical world to better understand contemporary processes of forced migration and his human impact.
\end{abstract}

\section{KEYWORDS}

Plutarco, forced migration, exile, sociology, precursors, classical world man.

\section{CONTENTS}

1. The forced migration in the classical world: exile and ostracism. 2. The ostracism and the defense of democracy in Athens. 3. The exile and loss of citizenship and identity. 4. De consolatio: Bridge from the classical world to the present. 5. Notes to a text of Plutarch: De exilio. References. 


\section{LAS MIGRACIONES FORZOSAS EN EL MUNDO CLÁSICO: DESTIERRO Y OSTRACISMO}

Las civilizaciones griega y romana no fueron, desde luego, ni las primeras culturas agrícolas y urbanas, ni los primeros imperios (Gordon Childe, 1976); tendríamos que irnos al valle del Indo en Mohenho Daro en el segundo milenio antes de nuestra era, al creciente fértil en torno al Tigris y el Éufrates, al valle del Nilo o, aún más lejos, a China, para encontrar los primeros focos urbanos y agrícolas sobre cuya existencia y recursos se construirían posteriormente las primeras formas de estado y organización política compleja (Redman, 1990:13-32). Pero el mundo clásico greco-latino es denominado así por nuestra propia cultura por los elementos de continuidad que perviven en nosotros de aquella tradición de la que procede nuestra estirpe. Si nos fijamos en la migraciones forzosas y las definimos como aquellos movimientos individuales o colectivos en los que se produce un abandono del ámbito espacial natural (originario queremos decir) y el traslado a otro distinto por causas externas a la voluntad -por la existencia de causas externas, coercitivasfijar la mirada sobre nuestro mundo clásico puede resultar enormemente clarificador.

La cultura griega desarrolló los conceptos de demos, logos, polis, políteia y tantos otros que aún conforman nuestra manera de entender la realidad, codificó las tensiones entre ciudadano, sociedad y estado, viendo aparecer el concepto de democracia y le dio a las relaciones políticas y sociales formas que hoy reconocemos pese a todas las salvedades que se quieran; el universo conceptual grecolatino sigue existiendo entre nosotros y hay unas líneas de continuidad cultural clarísimas que se remontan a casi tres mil años. No es tarea nuestra hacer esta síntesis, sino rescatar la experiencia del fenómeno de la migración forzosa en el mundo clásico y buscar algunos elementos que nos ayuden a poder interpretar en el presente la naturaleza profunda del fenómeno y una mirada a nuestra tradición clásica puede ayudarnos a clarificar la escena: no hemos sido los primeros en afrontar las migraciones forzosas y en reflexionar sobre ellas. Entre las múltiples miradas o, mejor, enfoques, con los que se puede abordar el mundo griego, la profesora Pérez Martín, nos recuerda dos posibles abordajes de la cuestión: el primero sería el emanado de la Grecia paradigma (Pérez Martín, 2001:11-16) nacida de la lectura directa de los autores clásicos más las interpretaciones del humanismo desde el Renacimiento hasta el siglo XX, y el segundo la Grecia historia, es decir, la Grecia "histórica", reconstruida desde sus fuentes en la medida en que el conocimiento y la investigación en historia, antropología y sociología, lo han permitido. Debemos recordar que prácticamente no hay ámbito del conocimiento en la actualidad que no pueda prescindir de algún tipo de diálogo con la Grecia histórica o con la Grecia paradigma, desde la historia, el derecho, la medicina, la sociología o la propia física (Prigogine, 1997:15-60). En este artículo realizaremos un breve repaso sobre algunas formas de las migraciones en el mundo clásico y analizaremos un texto de Plutarco de Queronea, autor griego tardío inserto ya en el mundo romano, en el que podremos encontrar luz sobre cómo interpretaban desde su propia cultura el fenómeno del destierro en tierra extraña con sorprendentes ecos de modernidad, hasta el punto de poderse considerar a este autor, Plutarco, como un precursor de la mirada sociológica.

Señala Claudio Guillen en su obra sobre el exilio en la literatura (Guillén, 1998:30-31), en la que hace un repaso de las trazas de éste que pueden rastrearse desde el mundo griego hasta la actualidad, que en la cultura clásica se encuentran dos tipos de referencias: el exilio como pérdida de la identidad y el exilio en tierra extraña, pero, al tiempo también el exilio como oportunidad para reflexionar sobre lo universal y la común identidad humana 
no importa donde estemos, siempre bajo el mismo sol y la misma luna, como escribiera Plutarco en su Sobre el destierro (1996). Es decir, encontramos dos presencias, una nos habla de la pérdida y otra de fusión con lo universal; dos percepciones opuestas, pero también asociadas como nos recuerda Guillen. Como hemos de volver a este lugar no insistiremos. Este destierro que evoca la obra de Plutarco y que es una de las formas de la migración forzosa, está relacionado también con otra figura, hoy en desuso, pero que es imprescindible que rescatemos pues pese a su carácter histórico la reflexión que hagamos a su amparo, desde su causa, es de gran utilidad actual. Nos referimos a la figura del ostracismo.

\section{EL OSTRACISMO Y LA DEFENSA DE LA DEMOCRACIA EN ATENAS}

La marcha desde las poleis arcaicas hasta la forma democrática de la Atenas del siglo $\mathrm{V}$ a.C. fue intensa y llena de luchas sociales (De Ste. Croix, 1998). Si los destierros y deportaciones fueron moneda corriente en las luchas entre poleis pero, sobre todo, dentro de estas, sería una medida tomada en el marco de las reformas de la constitución (políteia) de Atenas (Mossé, 1987:13-36) por Clístenes, la que le daría a una migración forzada por primera vez en la historia nombre propio y contenido democrático. El destierro fue una medida democrática por la forma en que se decidía y ppor la finalidad, cortar el paso a los que se consideraban un peligro para la comunidad. Las reformas de Clístenes, más la conmoción causada por las Guerras Médicas, abrieron el paso al gobierno en Atenas del demos (Mossé, 1987:29-36), el conjunto del pueblo, los ciudadanos libres, con independencia de sus riquezas. Entre esas medidas estaba el ostracismo y que cuyo sentido y procedimiento ha sido descrito así:

“(...) A Clistenes se le atribuye otra medida, el ostracismo, tendente a librar a la ciudad de aquellos individuos sospechosos para el conjunto del demos. El procedimiento era como sigue: en la reunión principal de la sexta pritanía (o presidencia por sorteo a ejercer por cada tribu) se decidía si durante el año en curso se quería realizar algún ostracismo; en caso afirmativo, tenía lugar unos meses después, en la octava pritanía, una votación con esa finalidad para la que parece que era necesario un quórum de seis mil ciudadanos. Cada uno de ellos escribía en un tiesto cerámico (ostrakon), el nombre de aquél que en su juicio merecía ser ostracizado. El ciudadano que recibiese una mayoría de votos en su contra era expulsado de Atenas durante 10 años, pero sin perder sus derechos políticos o sus propiedades".

Efectivamente, como señala Domínguez Monedero (1991), el ostracismo ligado a la democracia ateniense tiene la particularidad de ser un elemento para su defensa aunque el destierro forzoso era castigo común ejercido por los tiranos y del cual el propio reformador Clístenes había sido víctima.

“(...) Sean cuales sean las causas últimas de este procedimiento lo que parece cierto es que Clístenes ha introducido, nuevamente, un método para racionalizar la vida política ateniense. El mismo había experimentado la persecución política, aunque de signo contrario, tanto en época de Hipias como de Iságoras; posiblemente con este método (el ostracismo) inténtase evitar nuevas violencias, nuevas staseis (periodos convulsos marcados por la violencia y enfrentamientos) en una ciudad que, en los cien años previos había experimentado tantas" 
La voz ostracismo ha tenido en ocasiones un significado literal que ha sido mal interpretado. Una reconstrucción de la historia del concepto y del procedimiento la encontramos recogida en la Enciclopedia libre universal:

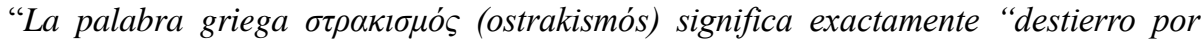
ostracismo”. La palabra ostrakon (ostrakon), quiere decir cáscara de huevo, caparazón de tortuga, concha en general, incluso las que están hechas de barro. También se refiere a un trozo de terracota en forma de concha donde se escribía el nombre de aquellos ciudadanos de la antigüedad que serían desterrados después de una votación. Era lo que se llamaba "castigo por ostracismo". El castigo por ostracismo, o simplemente ostracismo, era la fórmula o método por el cual se podía desterrar durante un cierto tiempo a un ciudadano no grato o peligroso para el bien común. La ley del ostracismo fue decretada en Atenas, en el año 510 a.C, y se puso en práctica en el año 487 a.C como lucha contra la tiranía. Primero fue condenado el político Hiparco, más tarde Megacles, Jantipo (padre de Pericles) y en el 482 a.C, Arístides, por sus enfrentamientos sociales a favor de los campesinos y en contra de las flotas marítimas. El último condenado se sabe que fue un demagogo ateniense llamado Hipérbolo, en el año 417 a.C. Para aplicar cada año la ley se reunía en Atenas la asamblea; votaban a mano alzada y si el resultado era positivo volvían a tener una votación pública dos meses más tarde. En esta votación cada votante escribía en el ostrakon (la concha de barro) el nombre de la persona a quien quería desterrar. Si el nombre de dicha persona alcanzaba una determinada cifra de votantes, tenía que marcharse de Atenas antes de 10 días y permanecer en el destierro durante 10 años. El exilio no era nunca permanente y además la persona exiliada no perdía jamás sus derechos como ciudadano e incluso podía ser perdonado por una nueva votación de la asamblea" (Varios Autores, 2009)

Nos encontramos ante una forma de migración forzosa individual que debemos calificar como sui generis. Es algo muy diferente a las proscripciones o a los destierros individuales o colectivos sufridos por los seres humanos en el marco de los conflictos entre tribus, pueblos o estados, o en la dinámica entre los individuos y éstos. Se trata de un sistema desarrollado para defender a la comunidad de ciudadanos de forma preventiva ante personas que habían acumulado mucho poder y que de alguna forma podían amenazar el gobierno de la mayoría; pero el ostracismo no implicaba ni la muerte física ni la muerte civil del ostracizado, estamos ante una forma extrema, dura si se quiere, de proscripción preventiva pero civilizada, autocontenida. Se respetaba su ciudadanía, sus propiedades y su nombre, obligando al condenado por la Asamblea a no regresar en diez años, pudiendo ser revocada la pena por el mismo procedimiento. El ostracismo no se practicó demasiadas veces, entre otras cosas por que la vida política de Atenas no fue ni tan apacible ni tan estable como Clístenes hubiera soñado. Las tensiones entre los ciudadanos se dieron con intensidad, viviéndose periodos de gobierno oligárquico, con el gobierno de la polis en manos de Ó Ø $\lambda_{i ́ r}$ or los Oligoi (la minoría si lo traducimos más exactamente, y en oposición a la mayoría, los polloi) -no necesariamente la minoría ilustrada (los KaloiKagatoi, es decir, los bellos y buenos), sino los poderosos y ricos-, con periodos de gobierno tiránico, en los cuales los tiranos eran apoyados por las clases populares para contrarrestar los poderes de los ricos. La inexistencia en la práctica de un sistema de garantías individuales hacía que ejercer la arqué o autoridad fuera el único sistema para encontrar la seguridad personal, luchando las mayorías populares contra las minorías 
poderosas para alcanzarla; ese es el contexto en el que nace el ostracismo, como un sistema para alejar del poder a quienes podrían convertirse en un problema para las libertades si alcanzaran la arqué; la comunidad de iguales se defiende, es la tiranía de la mayoría, en el sentido griego de la palabra, contra el peligro de los tiranos, los demagogos o los oligarcas. La democracia ateniense, no obstante sus contradicciones y su errática evolución, logró con el ostracismo una forma muy elaborada para autodefenderse, haciéndolo civilizada y humanamente, al menos en la forma propuesta por Clístenes y aprobada por los ciudadanos libres de Atenas.

Nos dice Mossé, en su célebre Historia de una democracia. Atenas, que si hoy en el mundo actual tiene algún sentido preguntarse sobre si los atenienses pueden aportarnos alguna enseñanza.

"Quizá la respuesta no sea posible. Pero lo cierto es que la civilización nacida hace dos mil quinientos años a orillas del Mar Egeo supo elaborar en menos de dos siglos un pensamiento crítico y político cuyas resonancias se han prolongado hasta nosotros, y que los atenienses tienen su puesto en la historia de los hombres que construirán el mañana” (Mossé, 1997:186)

\section{EL DESTIERRO Y LA PÉRDIDA DE LA CIUDADANÍA COMO IDENTIDAD}

Fustel de Coulanges en su clásica obra La ciudad antigua, incluye una vívida reconstrucción de lo que podía suponer para un ciudadano griego o romano ser sujeto de un destierro imperativo que le extrañara de su ciudad con todo lo que eso significaba en su cultura de referencia. Expone:

"El destierro era propiamente la interdicción del culto. Desterrar a uno era, según la fórmula usada igualmente por griegos y romanos, prohibirle el fuego y el agua, entendiéndose por este fuego el sagrado del hogar, y por el agua la lustral que servía para los sacrificios. El destierro arrojaba al individuo fuera de la religión.(...) Bajo el peso de esta excomunión, el desterrado no podía tomar parte en ninguna ceremonia religiosa, quedando privado de todo culto, de comidas sagradas y de preces, y desheredado de su parte de religión”" (Fustel de Coulanges, 1982:186)

En este texto, Fustel de Coulanges está hablando básicamente de la religión tradicional romana y de la posición más ortodoxa dentro de ella. Sigue:

"Conviene tener presente que en opinión de los antiguos, Dios no estaba en todas partes; y si tenían alguna vaga idea de una divinidad del universo, no era ella la que consideraban ni a la que invocaban como su providencia. Como los dioses de cada individuo eran los que habitaban su casa, su cantón y su población, el desterrado, al dejar su patria, los dejaba también. (...) Carecía de todo cuanto pudiera satisfacer las necesidades del alma” (Fustel de Coulanges, 1982:186-7)

Las escuelas helenísticas mantuvieron una posición diferente, pues su asunción de la relación entre el ser humano, la vida y la naturaleza, su religión, desarrolló varias líneas o escuelas que se apartaron en cierta medida de la Religión tradicional. Las escuelas helenísticas mantuvieron su existencia e incluso acrecentaron su influencia durante el Imperio Romano, siendo sus posiciones sobre el exilio o los efectos del destierro bastante diferentes como tendremos ocasión de ver. 
"Siendo la religión la fuente de que dimanaban los derechos civiles y políticos, claro es que el desterrado los perdía todos al perder la religión de su ciudad, también estaba excluido del culto doméstico y tenía que apagar su hogar. Sin derecho de propiedad, su tierra y todos sus bienes pasaban, como si hubiese muerto, a sus hijos, a menos que fueran confiscados en favor de los dioses o del Estado. Sin culto dejaba de tener familia, cesando de ser esposo y padre (...)" (Fustel de Coulanges, 1982:186-7)

Es decir, en la religión tradicional romana, el destierro era igual a la muerte religiosa lo que era igual a la muerte civil del desterrado.

"El desterrado -dice Jenofonte- pierde hogar, libertad, patria, mujer e hijos, y cuando muere no tiene ni el derecho de ocupar el sepulcro de la familia, porque es un extranjero». No es extraño, pues, que las repúblicas antiguas permitiesen casi siempre al culpable que evitase la muerte por medio de la fuga, porque no les parecía el destierro pena más benigna que la de muerte, y los jurisconsultos romanos la llamaban pena capital" (Fustel de Coulanges, 1982:186-7)

Hemos de decir que nos sorprende un poco la posición de Fustel de Coulanges en el sentido de referirse a «los antiguos» de forma un tanto intemporal, mezclando a griegos y romanos sin entrar a matizar cuando es necesario, como es por ejemplo, el caso de la religión, que en el caso romano es mucho más "domestica", y su relación con el destierro. En cualquier caso, la posición de Fustel de Coulanges es la de quien expone el modelo religioso ortodoxo dentro de la cultura romana, extendiéndose al mundo griego y cuanto nos informa sobre las implicaciones del destierro nos ayuda a visualizarlo mucho mejor.

Antes de seguir permítasenos recapitular lo visto sobre migraciones forzosas en el mundo clásico grecolatino. Por un lado tenemos una figura nacida del poder público ciudadano de la polis griega, el ostracismo. El ostracismo no implicaba la muerte civil definitiva del condenado sino su alejamiento forzoso como añadidura de la prohibición de participar en la vida política de la ciudad. No era fruto de una condena por un delito, sino un acto colectivo, votado por la Asamblea, de tipo preventivo, pudiendo ser además, reversible en cualquier momento.

Por otro lado, la figura del destierro. Una condena de los tribunales o de una magistratura con las competencias adecuadas para hacerlo, pero también como consecuencia de una decisión de la máxima autoridad del estado o la ciudad, en el caso de la Roma imperial, como consecuencia de un edicto emanado del Primer Ciudadano, dotado de la máxima Auctoritas et Imperium, esto es, el emperador o Cesar. El desterrado en estos casos afrontaba una situación equivalente a la muerte como ciudadano, obligado a extrañarse en tierra lejana, sin posibilidad de regreso casi siempre, lo que dadas las creencias religiosas y las características de la cultura romana era un pena equivalente a la de muerte, en el sentido de que ese individuo dejaba de existir socialmente, además de no estar ya presente físicamente nunca más en su ámbito originario. Destierro que implicaba también la pérdida de todas sus posesiones y lugar en la vida social de origen.

Nótese que ambas figuras, ostracizado y desterrado, son bien distintas. Pero ambas se refieren a ciudadanos de pleno derecho de su comunidad que pierden esa condición, si bien de forma y con alcances diferentes. Ciudadanía y estado, como vemos, son dos conceptos ligados al fenómeno. Fenómeno que se individualiza y toma nombre propio, se singulariza y concentra en una persona, aunque al cabo del tiempo puedan ser muchas personas. En la actualidad, la figura del refugiado en su acepción de la Convención del 51 es también personal, no es vista como un problema de masas, se trata como si de un problema individual 
se tratase y lo que se intenta es determinar si existió persecución individualizada contra el desterrado venido hasta nosotros.

¿Y entre quiénes no eran ciudadanos? En la Atenas del S.V a.C, se calcula la existencia de entre 30 y 50.000 mil ciudadanos para una masa de población superior al medio millón de personas, siendo muy difícil estimar la cuantía total en cualquier caso. Ni los menores de edad y esto incluía a todos los no emancipados con hogar propio, ni las mujeres, ni, por supuesto, los extranjeros libres, eran ciudadanos plenos. Y no olvidemos a los esclavos, la masa principal de la población.

Además de los destierros y proscripciones que podían afectar a ciudadanos de pleno derecho de la Ciudad Antigua, las migraciones forzosas eran protagonizadas principalmente por las poblaciones extranjeras enemigas que se podía ver sometidas a esclavitud. E igualmente por aquellas migraciones masivas de pueblos que impelidos por alguna razón llegaron en diversas fechas a las fronteras del mundo romano simbolizadas en ese Limes fortificado que separaba dos mundos.

Migraciones forzosas individuales o colectivas de ciudadanos por razón de destierro legal u ostracismo -siempre individual y sólo en el caso griego-, deportaciones y esclavitud de poblaciones vencidas de enemigos, migraciones masivas de pueblos que irrumpían en el espacio romano; estás serían las formas históricas de las migraciones forzosas. Nos preguntamos llegados a este punto si en el mundo clásico habría alguna muestra de reflexión escrita sobre lo que entrañaba el destierro. La respuesta casi nos sobrepasa: hubo incluso un género epistolar completo.

\section{4. de Consolatio: PUENTE DESDE EL MUNDO Clásico hasta EL PRESENTE}

En su obra Grecia clásica y mundo moderno, el helenista británico Murray señala que, en su consideración, la tradición griega escrita "tiene una nota de intimidad mucho más acusada que la de cualquier nación anterior y muchísimo mayor de lo que hay derecho a pedir a un pueblo en condiciones tan primitivas" (Murray, 1962: 27-30). Por "intimidad en la obra escrita", Murray se refiere a "la libertad interior con la que el autor se expresa", permitiendo al lector, incluido el lector de dos mil quinientos años más tarde, entrar en contacto con sus sentimientos y su forma de ver la vida. Esta intimidad se ve reflejada también en los textos latinos posteriores y quizá sea una de las causas de su enorme influencia posterior, precisamente esa capacidad para transmitir honradez y veracidad que demuestran los autores clásicos. La experiencia del exilio, de la migración forzosa, en quienes se educaron en una tradición religiosa que "re-ligaba" la tierra, la casa, los antepasados, la propia ciudad, con la vida civil y política tenía por fuerza que dejar fuertes huellas. La historia del estado romano (como la de Atenas) está llena de luchas por el poder en el seno de sus instituciones y también entre sus clases sociales y grupos de poder; fueron muchas las personas que a causa de esos conflictos y luchas se vieron despojadas de su ciudadanía y desterradas en mayor o menor grado, de forma más o menos irreversible. Una parte de esos desterrados dejaron obras escritas dando cuenta de sus más íntimas vivencias por causa del exilio; quizá el más famoso de todos ellos fue el caso del poeta Ovidio, desterrado más allá del Ponto, a Tomos, una aldea mínima en la desembocadura del Danubio en el Mar Negro, frontera del Imperio; de sus sufrimientos en tierra de Getas y Sármatas, allí donde Roma apenas estaba presente, Ovidio acabó de escribir su libro titulado Tristia (Ovideo Nason, 2001)(Tristes), obra de 
gran influencia y cuyos contenidos, hallazgos, temas y formas orientarían las literaturas del exilio hasta nuestros días (González Vázquez, 1998)

Además de las obras escritas por los propios desterrados, existieron otras que fueron escritas para los desterrados. Nos referimos a un género denominado Consolatio, o escritos consolatorios, que alcanzaría gran extensión y notoriedad. No se trata de que los destierros llenen por sí solos las consolatio, pues normalmente estos escritos se dedicaban a las penas $\mathrm{y}$ aflicciones causadas por la pérdida fatal de seres queridos, por enfermedad, vejez o cualquier otra desgracia. Pero el destierro era capaz de causar dolores y penas en modo parecido tanto al desterrado como a sus familias y cercanos, de forma que dentro del género de la consolatio, el destierro pasó a tener un lugar muy importante. Cid Luna, en su introducción a los Escritos consolatorios de Séneca, ofrece una interesante visión sobre este género, pero sobre todo sobre cómo las Escuelas helenísticas -cínicos y estoicos principalmente- influyeron en su contenido y evolución, dotando a las consolatio de una misión profunda de orientación humana y personal en épocas de dolor (Cid Luna, 1999: 15-27).

Sobre esta presencia en la literatura clásica del exilio y el destierro lo primero que percibimos desde nuestra propia época es la cercanía del dolor y la actualidad de los efectos del destierro que se describen. Han cambiado las formas políticas, ha evolucionado la técnica y el conocimiento, los antiguos imperios se han extinguido y de los viejos conflictos todo se ha olvidado, empezando casi por los nombres de los enfrentados y sus causas, pero la angustia que Ovidio transmite cuando escribe a bordo de la nave que le lleva al destierro sigue llegando hasta nosotros porque el ser humano actual no ha mudado su naturaleza en lo esencial.

En los Escritos de los desterrados (Ovidio), o en los Escritos para los desterrados (Plutarco, por ejemplo), encontramos un puente con el mundo actual que nos puede ayudar notablemente a dotar de las dimensiones correctas al problema humano del destierro en nuestra propia época.

No es solamente el problema del dolor por la disolución de la propia identidad en un lugar lejano, el de la pérdida del sistema de referencias y la desorientación consiguiente, es también la respuesta ética ante el trauma del exilio, la propuesta de estrategias morales para mitigar el dolor y ayudar a la integración de las personas en otras culturas apelando a lo que hay de universal y común en el género humano, lo que encontramos en la línea seguida por la mayoría de las consolatio de tradición helenística como muy bien nos recuerda Guillen en su estudio ya citado.

\section{NOTAS A UN TEXTO DE PLUTARCO: DE EXILIO}

En su obra El sol de los desterrados. Literatura y exilio Claudio Guillén señala que "el exilio es una realidad histórica social o personal" (1998:29-97) que existe evidentemente como existen también las posturas o conductas de las personas que lo viven, no debiendo reducirse unas a otras: es decir, nos señala Guillén, existe una parte objetiva, el fenómeno social que es proceso y que se puede objetivar, catalogar, describir, analizar, y también una parte subjetiva que es la forma en la que los individuos viven íntimamente esos procesos. Encuentra Guillén en la literatura clásica reflejo de dos posiciones básicas, polares.

En un caso -ya lo adelantamos anteriormente- estamos ante la posición del desterrado que se duele y lamenta del destierro y la pérdida, el empobrecimiento anímico y vital, y 
hasta la mutilación moral que éste puede causar (Guillén,1998:30)

En el otro, por el contrario, encontramos una guía moral para afrontar el hecho terrible del destierro buscando refugio en una interpretación cosmopolita del mundo, en una visión universalista de la vida, el ser humano y la naturaleza. Ovidio Nasón, representa el primer caso, Plutarco de Queronea el segundo.

Esas dos partes, la objetiva -el proceso de la migración forzosa con su juego de causas, factores y efectos-, y la subjetiva -la interpretación de los actores- son las que deben ser asumidas por una aproximación sociológica integral al fenómeno de la migración forzosa, entre otras cosas, porque en la interpretación subjetiva de los actores hay una relación dinámica con el entorno cultural de origen, no son dos mundos separados e inaprensibles el uno por el otro, sino que existe una conexión social en ambos extremos, el proceso colectivo objetivable como fenómeno y la interpretación individual subjetiva que está enmarcada siempre en un molde cultural por el que se ve influida y al que a su vez influye. Este planteamiento expresa muy bien la necesidad de afrontar el estudio de los procesos sociales con la incorporación de la perspectiva subjetiva de los actores, sustentada, por ejemplo, en las creaciones literarias, exactamente la propuesta metodológica de E.Morin sobre cómo orientar la sociología como ciencia con un objeto tan particular como el social (Morin, 19:16-17). Destaquemos también que el propio Claudio Guillén se hace eco de la perspectiva de Morin como particularmente necesaria para comprender la "complejidad de lo real" (Guillen, 1998:20-21) y que nosotros reclamamos también para afrontar el fenómeno de las migraciones forzosas, entre otros recursos como veremos.

Lo cierto es que los primeros escritos sobre el destierro y el exilio, es decir, sobre las consecuencias y vivencias de las migraciones forzosas, realizados con una finalidad entre descriptiva e interpretativa que nos atreveríamos a calificar de modernos surgieron en la cultura griega. Claudio Guillén nos informa con claridad:

"El primer libro o tratado en Occidente consagrado al tema del exilio del que tengamos noticia fue obra de Aristipo de Cirene, nacido hacia 425 a.C. y muerto en 355 a.C. Apunta Diógenes Laercio que circulaba un diálogo suyo titulado A los exiliados, y que Panecio de Rodas y Soción, el peripatético, le atribuían el tratado Los exiliados. "(Guillen, 1998:31)

Aristipo de Cirene, discípulo de Sócrates, defendía el disfrute del placer del alma y del cuerpo pero sin caer en su dependencia, siendo capaz de aceptarlo o sentir su ausencia en ambos casos con indiferencia. Aristipo dice en un diálogo con Sócrates que nos refiere Jenofonte: "Yo no me reduzco a ningún Estado en particular. Soy extranjero en todas partes". Desde Aristipo otros escritores y filósofos griegos tocan el tema del exilio, reflexionando sobre las desgracias que ocasiona y lo que procede asumir para encararlo. Serán las Escuelas Cínica y Estóica las que incluirán el problema del exilio en los aprendizajes sobre cómo afrontar los dramas de la vida. Trescientos años más tarde, ya en plena época romana, en torno al 96 d.C, un escritor griego, Plutarco de Queronea, escribirá una epístola a un amigo suyo desterrado, Sobre el exilio es el título con el que ha llegado hasta nosotros.

Procede analizar el contenido de la obra de Plutarco, pero antes de seguir conviene decir que sin la colaboración interdisciplinar este tipo de trabajos no podrían existir. El acceso a las obras clásicas exige o bien un conocimiento personal de la lengua y cultura en cuestión a un gran nivel de profundidad o la colaboración con los especialistas que ponen sus propios trabajos a disposición de la comunidad científica. Sobre la obra de Plutarco 
contamos en castellano con la aportación imprescindible R.Caballero, quien ha realizado su tesis doctoral sobre los aspectos filológicos de Sobre el exilio, realizando una nueva versión del texto original griego y contextualizando todas sus referencias y su estructura interna, si bien la exégesis que realiza es estrictamente filológica. R.Caballero ha publicado diversos artículos sobre este autor y podemos decir que su trabajo es básico y fundamental para afrontar el texto plutarquiano (Caballero, 2000:189-219; 1999). Por su parte, el también helenista Carlos García Gual ha dedicado un interesante artículo a una tardía manifestación neohelenista de las consolatio clásicas, -en concreto a una de las Epístolas familiares de Fray Antonio de Guevara-, donde se abunda igualmente en la obra de Plutarco y en la tradición greco-latina sobre este tema (García Gual, 1999). Los helenistas tienen su propia mirada, ciertamente distinta a la de los sociólogos -y en más ocasiones de lo que pudiera parecer coincidente-, pero su contribución puesta en común en el ámbito científico, nos ayuda a realizar el nuestro sin duda alguna. Si nuestra pretensión era analizar en cierta medida el fenómeno de las migraciones forzosas en el mundo clásico, después de contextualizar las formas del ostracismo y el destierro y de localizar un género epistolar como el de las consolatio procede que pasemos al contacto directo con el texto o, con lo que es igual, la propia voz de Plutarco (Plutarco, 1996).

Sobre sus intenciones Plutarco se explica en las primeras líneas de su obra, una excelente muestra del género denominado consolatio y del que ya hemos hablado. Dice Plutarco:

"1. Las palabras mejores y más seguras afirman que son, como los amigos, las que se presentan con provecho en las desgracias y sirven de ayuda. (...) Pues en situaciones involuntarias no tenemos necesidad de quienes lloran y se lamentan con nosotros como coros de tragedia, sino de quienes nos hablan con franqueza y nos enseñan que el entristecerse y el humillarse es inútil en cualquier ocasión y se convierte en cosa vacía e insensata, (...)” (Plutarco, 1996: $\left.\$ 1,1^{\circ}\right)$

Plutarco escribe para ayudar al lector, un amigo que ha sido desterrado, le exhorta a escuchar y a asumir sus palabras que no son de lamento sino de ánimo y están encaminadas a ayudar a hacer frente a la situación. Sigue:

"4. Pues bien, así como en la comedia un personaje exhorta a un amigo desafortunado a tener valor y hacer frente a la fortuna y, cuando éste le pregunta «¿de qué manera?», le responde, "de la manera propia de un filósofo», así también nosotros hagámosle frente obrando dignamente como filósofos" ( Plutarco, 1996:\$4, $1^{\circ}$ )

Hacer frente al infortunio del destierro en la forma en que lo haría un filósofo, ese es el mensaje. Sin duda es una de las primeras muestras de terapia psicológica de desarrollo de estrategias para afrontar situaciones íntimas difíciles. Plutarco que se ha formado en el conocimiento de Platón y su escuela, tiene no obstante, influencias muy importantes de otras tendencias de su propia época como la escuela estóica, muy presentes en las consolatio. Pero la posición de Plutarco combina respeto a Platón con ideas tomadas de estoicos y cínicos; el asunto principal de discusión es la defensa que hace Plutarco del cosmopolitismo y de una concepción universalista del hombre. Así le escribe a su amigo en el destierro:

“(...) Tal es tu actual traslado desde la que considerabas tu tierra patria (insano y vacío, objeto propio de tragedia). Pues no es patria por naturaleza, como no lo es tampoco casa, campo, herrería ni casa de médico, como decía Aristón, sino que se hace, o más bien se nombra y llama así cada una de éstas siempre en relación a quien 
la habita y la usa. Porque el hombre, como dice Platón, es «no una planta terrenal», ni inamovible, "sino celeste», en tanto que la cabeza como raíz sostiene derecho el cuerpo, dirigido hacia el cielo. Por esto, dijo bien Heracles:

argivo o tebano, porque no me jacto de ser

de una sola ciudad. Es mi patria

cualquier fortaleza de los helenos "(Plutarco, 1996: $\$ 5,2^{\circ}$ )

La lectura que podemos hacer desde la sociología moderna es clara. Plutarco comprende el dolor por la pérdida de la patria, pero intenta hacer ver a quien le lea, que la patria no es algo dado por naturaleza, sino que la patria es algo que se construye, algo en lo que nos educamos, la patria se hace, se nombra, se llena de contenido con la vida, es algo convencional, cultural diríamos con nuestro lenguaje actual. "Es mi patria cualquier fortaleza de los helenos", nos dice; "no es (la) patria por naturaleza (...) sino que se hace...", lo llega a explicitar.

Encontramos en Plutarco un planteamiento sociológico moderno; esta concepción de la patria como algo social, construido, algo que se hace, posibilita encontrar formas para cobijarse en otras patrias, en otros lugares, pues ayuda a mirar el mundo con otros ojos, aprendiendo lo que hay de exclusivo y lo que hay de común entre los pueblos, de forma que el sentido de pertenencia pueda ampliarse y enriquecerse. Por supuesto que acude a Platón, y emplea las referencias de la terminología platónica, ese es su contexto cultural personal y formativo además de las enseñanzas de los estoicos de su época, pero la idea básica es que la patria es algo que se construye y que hay otras referencias comunes o universales hacia las que podemos volvernos para buscar orientación en tiempos de destierro; estamos en el siglo I de nuestra era y un autor expone una concepción de la patria como algo "convencional", cultural, como una construcción social; esto basta para considerar a Plutarco y su personal visión entre platónica y estoica como un precursor de la sociología.

Insiste Plutarco en la idea cosmopolita y atribuirá a Sócrates lo siguiente:

“(...) Pero dijo mejor Sócrates, al afirmar que no era ateniense ni heleno, sino cosmio, como alguien podría decir rodio o corintio, porque no se encerró en Sunio, ni en Ténaro ni en los montes Ceraunios.

¿Ves en lo alto este infinito éter que sostiene en su entorno a la tierra en húmedo abrazo? Estas son las fronteras de nuestra patria y nadie es ni desterrado ni extranjero ni ajeno en ésas, donde hay el mismo fuego, agua, aire, y son magistrados, administradores y consejeros los mismos: sol, luna y estrella matutina. Las leyes son las mismas para todos bajo una sola orden y una sola autoridad: los Solsticios del norte y los Solsticios del sur, el Equinoccio, las Pléyades, Arturo, las estaciones de sembrar y las estaciones de plantar. Hay un solo rey y gobernante: «Dios, que tiene el principio, medio y fin de todo, avanza derechamente yendo en círculo conforme a su naturaleza. A él le sigue la Justicia, vengadora de los que faltan a la ley divina», de quien nos servimos todos los hombres por naturaleza respecto a todos los hombres como ciudadanos" (Plutarco, 1996:§5 3º-4º

De nuevo Plutarco nos sorprende. Al hacer suyas las palabras atribuidas a Sócrates nos dice que además de ser de tal o cual ciudad marcada por tales accidentes geográficos, somos además habitantes de una tierra común, el cosmos, de quien primero somos ciudadanos. Y el cosmos está regido por unas leyes naturales que son comunes en todas 
partes y que en última instancia son las que enmarcan el destino de todos como seres humanos. Es decir, más allá de la visión limitada del habitante de un sólo lugar que convierte a su terruño en centro del universo, para brindar consuelo al desterrado, Plutarco le recuerda que todos somos habitantes de un mismo mundo, regido además por leyes naturales a todos obligan y a todos nos hacen ciudadanos con independencia de donde hayamos nacido. Toda la comparación que establece y su mismo lenguaje es de clara impronta platónica, pero el empeño cosmopolita que pone en esa búsqueda de razones para el consuelo del desterrado nos muestra a un Plutarco que ha elaborado una opinión sobre temas que sin duda le preocupan a él muy personalmente; no se limita a unos consejos generales sobre el mal mayor o el mal menor, o como afrontar sin angustia lo inevitable como encontramos en la mayoría de las consolatio de impronta estoica, no; Plutarco expone, sucintamente pero con claridad, una teoría de la ciudadanía universal y del mundo como patria común de los seres humanos frente a las patrias convencionales, socialmente construidas, concepto este que llega a explicitar como hemos visto.

Insiste Plutarco en su visión cosmopolita:

“(...) ¿qué parte de la tierra habitada o de la tierra entera está lejos de otra cuando los matemáticos enseñan que respecto al cielo representa un signo sin extensión? Pero nosotros, como hormigas o abejas que salen de un hormiguero o de una colmena, nos atormentamos y nos sentimos extranjeros, sin saber ni aprender a mirar y considerar como nuestro el universo, como realmente es. Sin embargo, nos reímos de la simpleza de quien afirma que en Atenas la luna es mejor que la de Corinto, aunque en cierto modo nos sucede lo mismo, cuando al estar en país extranjero estamos inseguros sobre la tierra, el mar, el aire, el cielo, como si fueran otros y distintos de los acostumbrados. Pues, verdaderamente, la naturaleza nos deja libres y liberados, pero nosotros mismos nos atamos, nos estrechamos, encerramos entre muros, nos reducimos en lo pequeño y mezquino" (Plutarco, 1996:§6, 1º)

El análisis que se ha presentado aquí de este texto de Plutarco, y el rescate del ostracismo como instrumento de defensa de la democracia ateniense no agotan desde luego el problema de las migraciones forzosas en el mundo clásico, pero nos atrevemos a decir que resultaba necesario prestarles atención. Plutarco, un autor conocido pero quizá presente tan sólo en circuitos alejados de los estudios sobre migraciones o incluso del ámbito sociológico más usual, se nos revela como un claro precedente del pensamiento sociológico en un tema tan fundamental y actual como es la construcción social de la identidad.

La importante presencia de estudios sobre el refugio realizados desde el ámbito del derecho ha permitido que no falten referencias al fenómeno del asilo y su contenido religioso en el mundo clásico, o desde el ámbito de la filología y los estudios clásicos, los estudios sobre el destierro como topoi en la literatura clásica, entendíamos que dirigir nuestra mirada al mundo clásico podía resultar igualmente de interés. Hemos visto como en el seno de una cultura que es la base misma de la nuestra, se llegó a explicitar hace más de veinte siglos el problema de la pérdida de la identidad del desterrado, o cómo se propone una visión cosmopolita que permita afrontar el trauma del exilio.

El enfrentamiento entre el individuo y el colectivo, y entre el individuo y el estado aparecen también como algo central al fenómeno de la migración forzosa, no sólo la naturaleza puede empujar a los seres humanos a la marcha a lugares apartados por razón de una catástrofe o de una exigencia de la supervivencia, sino que también en el medio social 
que le es consustancial al ser humano, pueden darse casos de presiones imperativas que fuercen a la expulsión.

El mundo grecolatino elaboró discursos y estrategias de pensamiento para hacer frente a estos problemas, y sus propuestas -nos atrevemos a decir-, tienen la suficiente validez en la actualidad como afirmar que no se deberían afrontar problemas como el de la integración de los inmigrantes y el apoyo psicológico y social a los refugiados sin conocer nuestra propia tradición. En los tiempos actuales en los que el proceso de mundialización presenta el doble y contradictorio fenómeno de la disolución de identidades y de los conflictos de afirmación étnica, una de cuyas consecuencias secundarias es la migración forzosa, el ejemplo grecolatino de saber armonizar identidad con universalidad es más necesario que nunca. Plutarco, en su «Sobre el destierro», no solamente llevó consuelo a su amigo desterrado, sino que dos mil años después nos recuerda que las patrias y las identidades se hacen y que una misma luna y unas mismas estrellas son comunes a todos los seres humanos.

\section{BIBLIOGRAFÍA}

BRAUDEL, F. (1998), Memorias del mediterráneo. Prehistoria y antigüedad. Madrid: Cátedra.

CABALLERO, R. (1999), "La transmisión de los textos griegos en la antigüedad tardía y el mundo bizantino: una ojeada histórica", Tempus, 23.

CABALlERO, R. (2000), "Notas críticas y exegéticas al De exilio de Plutarco", en Cuadernos de filología clásica. Estudios griegos e indoeuropeos, nº10, pp.189-219.

CID LUNA, P. (1999), "Introducción”, en Séneca, L. A., Escritos consolatorios. Madrid: Alianza, pp.15-27.

DE ROMILLY, J. (1997), ¿Por qué Grecia? Madrid: Debate.

DE STE. CROIX, G.E.M. (1998), La lucha de clases en el mundo griego antiguo. Barcelona: Crítica.

DOMÍNGUEZ MONEDERO, A.J. (1991), La polis y la expansión colonial griega. Siglos VIII-VI. Madrid: Síntesis.

FUSTEL DE COULANGES, N.D. (1982), La ciudad antigua. Madrid: EDAF.

GARCÍA GUAL, C. (1999), "Los privilegios del estado desterrado según Fray Antonio de Guevara", en Archipiélago. Cuadernos de crítica de la cultura, 26:27.

GONZÁLEZ VÁZQUEZ, J. (1998), La poética ovidiana del destierro. Granada: Universidad de Granada.

GORDON CHILDE, V. (1976), Nacimiento de las civilizaciones orientales. Barcelona: Península.

GUILLÉN, C. (1998), Múltiples moradas. Ensayo de literatura comparada. Barcelona: Tusquets.

MORIN, E. (1995), Sociología. Madrid: Tecnos.

MOSSÉ, C. (1987), Historia de una democracia: Atenas. Madrid: Akal.

MURRAY, G. (1962), Grecia clásica y mundo moderno, Madrid: Norte y Sur.

ORTEGA MUÑOZ, J.F. (1999), La vuelta de Ulises. Madrid: Endymión.

OVIDIO NASÓN, P. (2001), Tristes. Pónticas. Madrid: Gredos.

PÉREZ MARTÍN, E. (2001), Los extranjeros y el derecho en la antigua Grecia. Madrid: Dykinson.

PLATÓN (2000), La república. Madrid: Alianza.

PLUTARCO (1996), Obras morales y de costumbres (moralia) VIII. Madrid: Gredos.

PRIGOGINE, I. (1997), El fin de las certidumbres. Madrid: Taurus.

REDMAN, Ch.L. (1990), Los orígenes de la civilización. Desde los primeros agricultores hasta la sociedad urbana en el Próximo Oriente. Barcelona: Crítica.

SÉNECA (1999), Escritos consolatorios. Madrid: Alianza.

VV.AA., "Ostracismo", en Enciclopedia Universal libre en español, disponible en: http:/enciclo pedia.us.es/index.php/Ostracismo, visitado 25/06/2009. 


\section{Breve currículo:}

\section{Pedro A. García Bilbao}

Doctor en Ciencias Políticas y Sociología por la UPSA, ejerce como profesor de Sociología Política en la URJC. Presidente del comité de investigación de Sociología de la Comunicación y del Lenguaje de la Federación Española de Sociología (FES). Investigador en la Cátedra de Estudios de la Defensa "Francisco Villamartín" URJC-CESEDEN y del GIESA -URJC (Grupo de Investigación en Estudios Sociales Avanzados). Miembro de la Cátedra China-España. Forma parte del Consejo de Redacción de la revista Didácticas Específicas (departamento de Didácticas específicas de la UAM). Sus líneas de investigación se centran en Sociología Política, Sociología de la Defensa, Cambio y Conflicto Social. Ha publicado, entre otros trabajos: Duxford. Museos militares e identidad democrática. (2012), Sociología de las migraciones forzosas. Concepto, dimensiones, teoría (2012). 